\title{
LIVROS E CANÇÕES: DIÁLOGOS ENTRE LITERATURA E MÚSICA
}

BOOKS AND SONGS: DIALOGUES

BETWEEN LITERATURE AND MUSIC

\author{
Joelma Santana Siqueira' \\ Victor Augusto da Costa Passos²
}

1 Doutora em literatura brasileira pela Faculdade de Filosofia, Letras e Ciências Humanas da USP (2008). Professora efetiva na graduação e pós-graduação da Universidade Federal de Viçosa e professora efetiva da Universidade Federal de Goiás/Campus Avançado de Jatai (2001-2004).

2 Graduado em Comunicação Social - Jornalismo pelo Centro Universitário do Leste de Minas Gerais (2012) e graduando em Letras na Universidade Federal de Viçosa. 
RESUMO: $\mathrm{O}$ artigo apresenta um relato reflexivo sobre o primeiro ano de um projeto de extensão intitulado "Livros e Canções", um programa de rádio apresentado semanalmente em uma emissora universitária. A partir do reconhecimento da importância da canção na cultura brasileira (Wisnik, 2004), do diálogo entre cultura erudita e popular (Bosi, 1992) e das emissoras de rádio universitárias a serviço da sociedade e contra os monopólios da informação (Deus, 2003), buscou-se apresentar diversas aproximações entre a cultura erudita e a cultura popular para o público ouvinte.

PALAVRAS-CHAVE: Literatura e canção; Extensão universitária; Literatura e mídia; Leitura.

ABSTRACT: The paper presents a reflective report of the first year of an extension project named "Books and Songs", a weekly radio program offered on a university station. Recognizing the importance of songs in Brazilian culture (Wisnik, 2004), of the dialogue between high and popular culture (Bosi, 1992), and of university radio stations at the service of society and against information monopolies (Deus, 2003), we sought to present the radio audience with different approaches to high and popular culture.

KEYWORDS: Literature and song; University extension; Literature and media; Reading. 


\section{INTRODUÇÃO}

A Fundação de Rádio e Televisão Educativa e Cultural de Viçosa (FRATEVI) foi criada em 02 de janeiro de 1990, com a finalidade de produzir e veicular programas de rádio e de televisão educativos e culturais, contribuindo para a melhoria do ensino e da cultura regional, em todos os níveis ${ }^{3}$. Dentro dessa perspectiva, o canal de Rádio da Fundação (Universitária FM 100,7) apresenta, atualmente, os seguintes programas voltados para a divulgação de notícias, cultura, ciência e educação: "100 Vírgula Rock”, “Baile Black”, “Disco Voador”, “Esquisito Rádio Clube”, “Madrugada Universitária”, “Momento Bossa Nova”, “Na Área”, “Primeira Classe”, “Rádio Aspuv”, “Samba no Prato”, “Tarde Universitária”, “Viola Sertaneja”, “Zip Zap”, “Almoço com MPB”, “Ciência no Ar”, “Espaço Universitário”, “Manhã Universitária”, “Musical Box”, “Papo Educação”, "Programa Sônia Sant'Anna”, “Reunião da Câmara Municipal de Viçosa”, “Seleção Musical”, “Universitária Notícias,' “Voz do Brasil” e “Livros e Canções”. É sobre este último que trata o presente artigo, propondo uma reflexão a respeito das atividades realizadas no decorrer do ano de 2019, primeiro ano do projeto.

O programa "Livros e canções" foi criado em 2019, após aprovação do projeto no Edital 04/2018 da Pró-Reitoria de Extensão e Cultura da Universidade Federal de Viçosa, que teve como objetivo geral apoiar projetos de extensão universitária que estivessem em consonância com a Política Nacional de Extensão Universitária e Política de Extensão da Universidade Federal de Viçosa por meio de bolsas para estudantes de graduação ${ }^{4}$.

A Política Nacional de Extensão Universitária (PNE) foi apresentada às Universidades Públicas e à sociedade brasileira pelo Fórum de Pró-Reitores de Extensão das Universidades Públicas Brasileiras (FORPROEX). O documento mais recente foi aprovado durante o XXXI Encontro Nacional, realizado em Manaus (AM), em maio de 2012. Os objetivos propostos foram formalizados no Plano Nacional de Extensão Universitária,

3 Disponível em https://fratevi.org.br/pagina-sobre. Acesso em 10 jan. 2021.

4 Disponível em http://www.pec.ufv.br/wp-content/uploads/2018/09/EDITAL-PIBEX-2019.pdf. Acesso em 10 jan.2021. 
de 1999, acrescidos de outros que, conforme esclarece o documento, são "necessários para o enfrentamento de novos desafios e aproveitamento de novas oportunidades, tendo em vista o contínuo fortalecimento da Extensão Universitária” ${ }^{5}$. Entre os objetivos presentes no documento, para o âmbito do projeto “Livros e Canções", destacamos:

- estimular atividades de Extensão cujo desenvolvimento implique relações multi, inter e ou transdisciplinares e interprofissionais de setores da Universidade e da sociedade;

- possibilitar novos meios e processos de produção, inovação e disponibilização de conhecimentos, permitindo a ampliação do acesso ao saber e o desenvolvimento tecnológico e social do País;

- estimular a utilização das tecnologias disponíveis para ampliar a oferta de oportunidades e melhorar a qualidade da educação em todos os níveis;

- considerar as atividades voltadas para o desenvolvimento, produção e preservação cultural e artística como relevantes para a afirmação do caráter nacional e de suas manifestações regionais.

Além dos objetivos acima, consideramos relevante destacar que, entre as áreas de atuação prioritárias na articulação da Extensão Universitária com as políticas públicas, a Política Nacional de Extensão Universitária propõe que esteja incluída "a promoção do desenvolvimento cultural, em especial a produção e preservação de bens simbólicos e o ensino das artes”.

A partir dessas proposições e do reconhecimento da importância de contar com uma emissora de rádio universitária como um laboratório para as diversas áreas de conhecimento da instituição, elaboramos o projeto com o objetivo geral de criar um programa de rádio semanal sobre livros e canções, com ênfase na divulgação de conhecimento, estímulo à leitura e à fruição de um repertório de canções significativas de nossa vida cultural. Como objetivos específicos, destacamos:

5 Disponível em http://www.pec.ufv.br/wp-content/uploads/2016/05/2012-07-13-Politica-Nacional-de-Extensao.pdf. Acesso 10 jan. 2021.

$6 \quad$ Idem. 
- Divulgar de modo criativo conhecimentos sobre livros e canções.Contribuir para a fruição da leitura e da escuta musical.

- Divulgar obras e informações relevantes para a formação do público.

- Incentivar o desenvolvimento de processos criativos relacionados à leitura e à escuta de canções.

- Sensibilizar para a convivência e o respeito à diversidade de obras e gêneros literários e musicais.

- Incentivar o reconhecimento da importância da cultura popular e da cultura erudita.

- Contribuir para reflexão sobre a realidade social a partir da apreciação de livros e canções.

- Contribuir para a programação da Rádio Universitária FM como ferramenta a serviço da sociedade e contra os monopólios da informação.

- Contribuir para ampliar o público ouvinte da Rádio Universitária FM.

- Promover a formação extracurricular da equipe envolvida na execução do projeto.

- Contribui para a socialização das pesquisas desenvolvidas no Departamento de Letras da Universidade Federal de Viçosa.

\section{JUSTIFICATIVA}

Antes de iniciarmos o projeto, acompanhávamos como ouvinte a programação da Rádio Universitária FM 100,7, e apesar de considerarmos que se tratava de uma excelente programação cultural e educativa, percebíamos que não possuía um único programa voltado para o incentivo à leitura, ou que falasse de livros ou de literatura. Diante dessa constatação, observamos que o projeto poderia contribuir para a responsabilidade social que as emissoras de rádio universitárias públicas devem ter, concordando com a professora Sandra de Deus (2003, p. 311), no artigo intitulado "Rádios Universitárias Públicas: compromisso com a sociedade e com a informação", sobre a importância dessas rádios serem usadas como ferramenta da universidade a serviço 
da sociedade e contra os monopólios da informação, portanto, voltadas à divulgação de todas as formas de expressão "que os modelos de radiodifusão comercial ignoram". Além disso, pensamos na importância que tem a canção na cultura brasileira, dado seu poder de atração do público ouvinte, mas também seu poder de absorção e diálogo com a literatura. Sobre essa questão, muitos estudiosos têm realizado excelentes trabalhos, entre eles, o professor, músico, compositor e ensaísta José Miguel Wisnik, autor de vários ensaios dedicados ao assunto, em especial, o ensaio "Gaia ciência: literatura e música popular no Brasil”, no qual, após elencar uma série de exemplos de elementos musicais e poéticos ocorridos a partir dos desdobramentos da bossa nova, citando Nietzsche, escreveu:

Podemos postular que se constitui no Brasil, efetivamente, uma nova forma de 'gaia ciência', isto é, um saber poético musical, que implica uma refinada educação sentimental (como aquele assim designado pelos trovadores de Toulouse no século 16, lembrando a grande tradição provençal do século 12) mas, também, 'uma segunda e mais perigosa inocência na alegria, ao mesmo tempo mais ingênua e cem vezes mais refinada do que ela pudesse ter sido jamais' (a frase é de Nietsche na abertura de Gaia Ciência) (WISNIK, 2004, p.218).

Portanto, também pensando na "gaia ciência" que, no Brasil, envolve a canção como um saber sensível e refinado, o projeto "Livros e Canções" passou a fazer parte da programação da Rádio Universitária FM 100,7 a partir de abril de 2019, ao lado de outros programas relevantes para a divulgação da informação, ciência, educação e cultura, desenvolvidos com a participação de pesquisadores de diferentes cursos da instituição e realizando aquilo que Edson Luiz Spenthof (1998, p.153), no artigo "A importância das rádios e TVs universitárias como laboratórios", considerou ser as quatro funções que justificam a existência desses canais: "a divulgação da produção universitária, a canalização da política de extensão das universidades, a atividade laboratorial e a democratização da comunicação e do conhecimento". 


\section{FUNDAMENTAÇÃO TEÓRICA}

Em 2020, a Plataforma Pró-Livro publicou a $5^{\text {a }}$ edição da pesquisa Retratos da Leitura no Brasil ${ }^{7}$. Sobre os resultados apresentados, o professor José Castilho Marques Neto, no artigo "Políticas públicas de livro e leitura no Brasil - o que as pesquisas Retratos da Leitura nos revelam" ${ }^{8}$, ressaltou que perdemos $4 \%$ de leitores no último quadriênio, pois a $4^{\text {a }}$ pesquisa, de 2015 , computava $56 \%$ de leitores (104,7 milhões de pessoas), enquanto a $5^{\text {a }}$ pesquisa, de 2019 , apresentou $52 \%$ (100,1 milhões de pessoas). A definição de leitor para a referente pesquisa é “aquele que leu, inteiro ou em partes, pelo menos um livro nos últimos três meses" ${ }^{\prime}$. Uma definição que desconsidera a coexistência do livro com outras formas de inscrição e de comunicação dos textos, como a da textualidade eletrônica, algo que Roger Chartier (2002, p. 107), no ensaio “Morte ou transfiguração do leitor?”, originalmente publicado em 2000, considerava tratar-se de uma hipótese "mais sensata do que as lamentações sobre a irremediável perda da cultura escrita ou os entusiasmos sem prudência que anunciavam a entrada imediata de uma nova era da comunicação".

Para a professora Mirian Hisae Yaegashi Zappone, em texto publicado no blog do Grupo de Estudos em Literatura Brasileira Contemporânea, a pesquisa Retratos da Leitura no Brasil tem servido para que se relativize a ideia de que o brasileiro é um não leitor e de que não gosta de leitura. Seu texto aborda os dados das quatro primeiras pesquisas $(2000,2007,2011$ e 2016) e, para as pessoas que consideram os dados da leitura no Brasil com pessimismo, ressaltou:

na França, uma pesquisa semelhante realizada em 1989 detectou um índice de $49 \%$ de leitores efetivos, o que equivalia a 23,5 milhões

7 Disponível em < http://plataforma.prolivro.org.br/retratos.php > Último acesso em 10 jan. 2021.

8 Disponível em < https://www.prolivro.org.br/2020/11/12/politicas-publicas-de-livro-e-leitura-no-brasil-o-que-as-pesquisas-retratos-da-leitura-nos-revelam/> Último acesso em 10 jan. 2021.

9 Disponível em < https://www.prolivro.org.br/5a-edicao-de-retratos-da-leitura-no-brasil-2/a-pesquisa-5a-edicao/> Último acesso em 10 jan. 2021. 
de leitores. Portugal, em 1995, tinha um índice de 37\% dessa mesma categoria de leitores. Como se vê, nossos 56\% de leitores efetivos são expressivamente numerosos ${ }^{10}$.

A $5^{\text {a }}$ pesquisa realizada pelo Instituto Pró-Livro, em 2019, também lançou Retratos da Leitura em Bibliotecas Escolares e Retratos da Leitura em eventos do livro e literatura, visando, como informa na plataforma do instituto, "conhecer outros leitores, espaços e desafios para a formação do leitor e o acesso ao livro" ${ }^{11}$.

Para além da leitura do livro, no âmbito do projeto "Livros e Canções", consideramos importante pensar a canção como objeto de leitura que, muitas vezes, absorve ou dialoga com a literatura, mas, também, com outros saberes. A esse respeito, consideramos importante reproduzir aqui o comentário de José Miguel Wisnik presente no documentário "Palavra (En)Cantada":

A cultura no Brasil é muito oral, muito rítmica, muito musical, muito corporal e muito festiva. Acho que a literatura, quer dizer, a cultura letrada, nunca se implantou completamente no Brasil, no sentido de você ter uma vida, uma vida cultural baseada em publicações, leituras, grandes números de leitores. Passou-se muito diretamente dos meios orais pro rádio, pra televisão, pra os meios audiovisuais. Eu sinto o quanto a literatura, aliás, o quanto a música popular no Brasil, ela é uma ponte que junta, por exemplo, para as gerações que chegam, que a gente vai ensinar literatura, o quanto a música popular permite você estabelecer um contato entre a literatura e o repertório desses alunos, dessas gerações. Criou-se uma situação em que não existe propriamente em país nenhum desse jeito, que é uma canção popular fortíssima, que ganhou uma capacidade de falar pra, quer dizer, de cantar pra auditórios imensos e levar pra esses auditórios poesia de densa qualidade, de sutileza, de riqueza e ao mesmo tempo de essa imediatez, essa leveza que a canção também tem (WISNIK, apud SOLBERG, 2009).

10 Disponível em http://gelbcunb.blogspot.com/2017/04/as-dificuldades-da-leitura-no-brasil. html?spref=fb Último acesso em 10 jan. 2021.

11 Disponível em < http://plataforma.prolivro.org.br/retratos.php\#: :text=Os\%20Retratos\%20 da\%20Leitura,0\%20comportamento\%20leitor\%20do\%20brasileiro> Último acesso em 10 jan. 2021. 
O documentário "Palavra(En)Cantada" ganhou o prêmio de melhor direção de longa metragem documentário do Festival do Rio em 2008. O comentário de Wisnik sobre a existência de uma ponte entre literatura e música, ou entre música e literatura, a funcionar para o ensino de literatura pode ser verificado, por exemplo, no ensaio “Machado Maxixe: o caso Pestana", em que o ensaísta analisa a presença da música na narrativa machadiana, refletindo sobre diversos aspectos da estrutura da narrativa que dialogam com a estrutura musical (da polca e do maxixe) e com nossa história social, tendo em vista também as relações entre o erudito e o popular em nossa cultura.

Outro exemplo dessa ponte pode ser verificado no ensaio do compositor, crítico, ensaísta e diretor artístico Arthur Nestrovski, intitulado O samba mais bonito do mundo e, não por acaso, publicado no mesmo volume da Revista Teresa em que José Miguel Wisnik (2003) publicou o ensaio Machado Maxixe: o caso Pestana, um dossiê dedicado ao tema "Literatura e Canção". Nestrovski (2003, p.137) identifica na letra de "Águas de março", de Tom Jobim, aproximação com o poema “O caçador de esmeraldas", de Olavo Bilac, e com um ponto de macumba gravado por J. B. de Carvalho, do Conjunto Tupi; na melodia, destaca "requintes comparáveis aos de Schumann e Schubert". Considera, portanto, que, na música de Tom Jobim,

o modo como a alta cultura se cruza com as reproduções populares (Bilac e macumba, Schumann e samba) - atinge um grau de realização tão mais notável por assumir uma forma assim generosa e modesta, sem afetação nenhuma. O minério da canção renderá mais e mais riqueza, para quem se debruçar sobre a partitura; mas na hora da escuta nada chama a atenção para minúcias do artesanato (NESTROVSKI, 2004, 139).

O comentário de Wisnik sobre a oralidade presente em nossa cultura também se aproxima do que disse a professora Marialva Barbosa (2015), na ocasião em que, exercendo a função de presidente da Sociedade Brasileira de Estudos Interdisciplinares da Comunicação - Intercom, foi entrevistada pelo grupo de pesquisa "Livros e Cultura Letrada", da Faculdade de Comunicação Social da UERJ. Entre outros aspectos, esclareceu que em seu livro História da comunicação no Brasil (2013) pretendeu mostrar que "as práticas de comunicação no Brasil são governadas pelas práticas da oralidade, ou seja, que nós somos orais por excelência e que passamos da orali- 
dade 'primária' para a oralidade dos meios de comunicação eletrônicos, até chegar aos eletroeletrônicos e depois aos digitais, sem nunca ter passado pelo letramento" (BARBOSA apud GUIMARÃES, 2015, p. 147).

Segundo Marialva Barbosa, não se trata de oposição entre oralidade e letramento, posto que as práticas culturais podem dar-se em vários tipos de construções culturais sem que envolvam essa visão binária, "assim como não há oposição entre cultura letrada e cultura não letrada, tão estudada desde Bakhtin, e também por todos os autores que estudam na História a questão da cultura" (p. 148). Suas palavras lembram-nos do ensaio "Cultura brasileira e culturas brasileiras", do estudioso da literatura Alfredo Bosi (1992, p. 331), sobretudo quando destaca que, do contato entre a cultura erudita e a cultura popular podem resultar coisas ruins, "que vão do mais cego e demagógico populismo", mas, também, coisas excelentes, “como a música de Villa-Lobos, o romance de Guimarães Rosa, a pintura de Portinari e a poesia negra de Jorge de Lima".

Muitas aproximações e diálogos entre a cultura erudita e a cultura popular, porém, são pouco reconhecidas do público não especializado. O professor de Linguística, compositor, cantor e estudioso da canção Luiz Tatit, em entrevista publicada na Plataforma do Letramento, ao ser perguntado se o universo da música e das canções pode influenciar no letramento das crianças e jovens, iniciou sua resposta destacando que, no Brasil, a audição de rádio, atualmente pelos vieses da internet,

tem mais importância do que propriamente a vida literária ou a vida mais intelectualizada, como se concebia anteriormente. Quer dizer, o estudante para se desenvolver precisaria ter acesso a livros, a leituras de livros didáticos ou literatura. E hoje a gente vê que os estudantes se interessam muito mais por canções e bandas de rock, bandas de toda natureza que surgem por aí, do que propriamente se equipar com essa parte toda mais artística ou mais literária que já está consagrada. Na verdade, o que se frui atualmente é uma atividade ainda não consolidada, ainda não consagrada, do ponto de vista acadêmico, que é o mundo da canção ${ }^{12}$.

12 Disponível em Luiz Tatit: letra e música na canção popular. Entrevistas - Plataforma do Letramento Acesso em 10 jan. 2021. 
Destacando a importância do mundo cancional e definindo-o como o mundo em que se tem melodia e letra atuando simultaneamente, na entrevista acima, Tatit considerou que é por meio da canção que o jovem entra no mundo da cultura brasileira.

\section{METODOLOGIA}

O projeto foi primeiramente idealizado no Departamento de Letras, a partir de discussões entre discentes e docentes que fazem parte de Grupo de Pesquisa do CNPq “Literatura e mídia”, e que reúne projetos de pesquisa, ensino e extensão sobre as relações entre literatura e os meios de comunicação, envolvendo a imprensa, o rádio, a televisão, o cinema e a internet, visando o diálogo entre essas instâncias, bem com as influências materiais, a historiografia e a crítica cultural. O grupo possui um site institucional onde tem publicado relatórios, artigos, áudios e vídeos produzidos a partir de projetos de Pesquisa, Ensino e Extensão realizados pelos pesquisadores. O endereço do site é www.literaturaemidia.ufv.br.

A equipe do projeto foi composta por uma professora do curso de Letras, coordenadora do projeto, um estudante de graduação bolsista da Pró-Reitoria de Extensão e Cultura, um gerente de rádio, um diretor de programação da rádio e sete discentes de graduação voluntários. As reuniões aconteciam com uma frequência média de duas vezes ao mês, para discussão sobre seleção das obras, pesquisa, elaboração, revisão e gravação dos roteiros no estúdio da Fretevi.

Qualquer membro da equipe poderia propor roteiros que, antes de gravados, passavam por avaliação e correção realizadas pela equipe. A orientação incluía pesquisa em livros, sites, encartes, vídeos, revistas etc. para que cada roteiro trouxesse uma síntese de informações relevantes sobre o livro, visando estimular a leitura pelo público, seguidas de informações sobre inter-relações entre a obra literária e a canção tocada durante o programa. Uma exigência a que todo proponente de roteiro esteve submetido foi a leitura na íntegra da obra literária a ser apresentada no programa. 


\section{ATIVIDADES REALIZADAS}

Em 2019, publicamos 23 programas do projeto "Livros e Canções” na Rádio Universitária FM 100,7, que também pode ser acessada pela internet no endereço https://fratevi.org.br/paginas/radioPlayer.php. Na página do projeto no Facebook13, publicamos comentários de 17 programas, convidando o público a acompanhar a programação da rádio e a acessar os programas no site do Grupo de Pesquisa "Literatura e Mídia”. As obras literárias abordadas nos programas gravados em 2019 foram: Música do Parnaso (1705), de Manuel Botelho de Oliveira; Pauliceia Desvairada (1922), de Mário de Andrade; Grande sertão: veredas (1956), de João Guimarães Rosa; Clarissa (1933), de Érico Veríssimo; Torquatália: obra reunida (2004), de Torquato Neto; Algaravia: câmara de ecos (1996), de Waly Salomão; Antologia poética (1954), de Vinícius de Moraes; Azul e lindo: planeta terra, nossa casa (1990), de Ruth Rocha e Otávio Roth; O Pequeno príncipe (1943), de Antoine de Saint-Exupéry; Admirável mundo novo (1932), de Aldous Huxley; 1984 (1949), de George Orwell; O conto da Aia (1985), de Margaret Atwood; José (1942), de Carlos Drummond de Andrade; Minhas saudades (1989), folheto de Antônio Pereira. Cinco programas apresentaram entrevistas com estudiosos da literatura e foram dedicados a discussões de obras de João Cabral de Melo Neto, Clarice Lispector e José Saramago. Um programa foi concebido como resposta a uma dúvida de um ouvinte e ganhou o título "Literatura e música (Wisnik, Machado, Nazareth)”. Todos os programas estão disponíveis no endereço https://literaturaemidia.ufv.br/projetos/livros-e-cancoes-2/ para acesso livre do público.

No início e no final de cada roteiro dos programas, tivemos vinhetas fixas, criadas ao som da canção “Outras palavras”, de Caetano Veloso, gravada no álbum homônimo, de 1981. Visando estimular o trabalho criativo capaz de despertar o interesse do público ouvinte, não estabelecemos uma estrutura fixa para os roteiros. Alguns foram compostos com citações de passagens do texto literário, seguidas de comentários críticos estimulantes e comentários sobre os vínculos com uma canção tocada durante

13 Disponível em <https://www.facebook.com/UmProgramadaRadioFratevi> Último acesso em 10 jan. 2021. 
o programa. Outros foram realizados a partir de entrevistas com leitores estudiosos da obra de determinado escritor, instigados a comentarem também sobre possíveis relações com alguma canção tocada durante a entrevista. Em síntese, cada roteiro foi composto com informações relevantes sobre uma obra literária, visando estimular a sua leitura pelo público e seguidas de comentários sobre inter-relações com uma canção reproduzida ao longo do programa. A duração de cada roteiro variou entre sete e quinze minutos, com publicação toda terça-feira, por volta das 13 horas, e reprises às quintas e domingos, por volta das 10 horas da manhã.A estreia do programa ocorreu no dia 23 de abril de 2019, data escolhida pela UNESCO para comemorar o Dia Mundial do Livro. A obra selecionada para essa estreia do programa foi Música da Parnaso (1705), de Manuel Botelho de Oliveira. Nas palavras presentes no roteiro abaixo podemos entender o motivo dessa escolha:

ESTÁ NO AR “LIVROS E CANÇÕES - UM PROGRAMA QUE LEVA VOCÊ DO LIVRO À CANÇÃO E DA CANÇÃO AO LIVRO”.

\title{
(Vítor):
}

Olá! Eu sou Victor Passos e abro o primeiro bloco do programa "Livros e canções" com livros de literatura brasileira que trataram de lugares. Nosso primeiro livro Música do Parnaso, foi publicado em 1705, em Lisboa, por Manuel Botelho de Oliveira. Trata-se de uma coletânea de poesias escritas em português, espanhol, italiano e latim. Os versos circularam primeiramente de forma manuscrita. Na dedicatória do livro, Botelho informa que decidiu publicá-lo para ser ao menos o primeiro filho literário brasileiro a ter um livro publicado. $\mathrm{O}$ poema mais conhecido é dedicado à Ilha de Maré. Vamos ouvir um fragmento na voz de Luiza Martins:

\author{
(Luiza): \\ VISTA POR FORA É POUCO APETECIDA, \\ PORQUE AOS OLHOS POR FEIA É PARECIDA; \\ PORÉM DENTRO HABITADA
}




\section{É MUITO BELA, MUITO DESEJADA, É COMO A CONCHA TOSCA E DESLUSTROSA, QUE DENTRO CRIA A PÉROLA FERMOSA".}

(Vitor):

Patrícia de Sousa, o que você pode nos dizer sobre esse poema?

\section{(Patrícia):}

Olá, Victor, olá ouvinte! O poema "Ilha de Maré" louva a natureza dessa bela ilha, que, segundo o eu-lírico, possui frutas deliciosas, maiores e melhores que as da Europa.

(Vítor)

E existe uma ilha com esse nome na Bahia?

\section{(Patrícia):}

Sim, a Ilha de Maré está localizada na baía de Todos os Santos e pertence à cidade de Salvador. Os moradores são, principalmente, pescadores e artesãos. Sobre ela, Walmir Lima compôs uma canção que foi primeiramente gravada por Alcione, em 1977. Vamos ouvir a canção com o convite para conhecermos o poema de Manuel Botelho e sua ilha de maré:

(Tocamos a canção gravada por Alcione)

(Vítor)

ACABAMOS DE OUVIR “ILHA DE MARÉ”, NA VOZ DE ALCIONE, COM O CONVITE PARA A LEITURA DO POEMA DE MANUEL BOTELHO DE OLIVEIRA E UMA VISITA A ESSA ILHA, QUE FICA BEM PRÓXIMA À CIDADE DE SALVADOR, BAHIA.

\section{ANÁLISE}

Como é possível perceber, o primeiro programa foi uma homenagem da equipe 
ao primeiro autor nascido no Brasil Colônia, Manuel Botelho de Oliveira. Sua obra Música do Parnaso foi publicada em 1705 e a passagem mais conhecida é o poema "À Ilha de Maré", que descreve a natureza tropical como superior às demais. Demos informações relevantes sobre o autor e sua obra, lemos passagens do poema e destacamos que a Ilha de Maré é uma ilha de Salvador. Não nos aprofundamos, porém, na análise do poema e da canção. O vínculo criado entre o poema e a canção foi apenas a coincidência do espaço geográfico, a Ilha de Maré. Reconhecemos, posteriormente, que poderíamos ter realçado a distância entre os dois textos, observando que a canção não se prende à ilha, destacando sobretudo a festa da Lavagem do Bonfim, que acontece todo ano na cidade de Salvador e tem importância religiosa e cultural para a capital da Bahia. Poderíamos, também, ter informado que a Ilha de Maré é menos conhecida do que a Ilha de Itaparica e que, talvez por isso, permaneça sendo um lugar com belas praias resguardadas e povoados intocados à beira-mar, de cultura tradicional viva, que ainda sobrevive da pesca e do artesanato. A canção que foi tocada tem título homônimo do poema, "Ilha de Maré", composta por Walmir Lima e gravada por Alcione em 1977, fez do compositor o autor de um dos mais conhecidos sambas baianos, assunto que é narrado no livro reportagem Walmir Lima: além da Ilha de Maré - a história de um sambista (2017), de Luciana Melo.

Conforme relatado acima, todos os programas eram avaliados para que os próximos pudessem ser aprimorados. A falha mais recorrente foi termos produzido comentários reduzidos a respeito das canções, quase sempre restrito a informações sobre a primeira gravação, nome do compositor e intérpretes, deixando de realizar com mais apuro uma análise comparativa entre o texto e a canção, algo que pretendemos corrigir na próxima temporada do programa.

Para acompanhar o impacto social do projeto, foi criado um perfil do programa nas redes sociais a fim de divulgar a programação e acompanhar a adesão do público. O acompanhamento de alcance e engajamento do público deu-se, principalmente, por meio da página do projeto no Facebook. Dados estatísticos do recorte temporal de abril de 2019 a abril de 2020 dessa página indicam 271 curtidas, tendo como público total mais recorrente o da faixa-etária de 25 a 34 anos. Em relação ao gênero, 
$68 \%$ foi composto por mulheres e $32 \%$, por homens. A página também contou com interação de usuários situados fora do Brasil, sendo 4 usuários em Portugal, 2 Itália, 1 Angola, 1 Países Baixos e 2 nos EUA. As publicações nesta rede social mantiveram em média um alcance de 300 usuários, alcançando o pico de 1300 com o programa de entrevista sobre a obra da escritora Clarice Lispector. Além disso, a coordenação do projeto recebeu pessoalmente muitos feedbacks positivos do público, informados por colegas da Universidade Federal de Viçosa, pessoas da cidade e ex-alunos do curso de Letras da instituição que acompanharam as postagens no Facebook e ouviram os programas disponíveis no site do Grupo de pesquisa "Literatura e mídia”. Com relação ao impacto social esperado, portanto, considerou-se que a proposta impactou o público por força da regularidade e da qualidade da programação. Vale destacar que a rádio pode ser acessada pela internet e que, em 2019, a estimativa de acesso online no horário do programa foi de 12 mil ao ano, de acordo com informação fornecida pelo gerente de rádio membro da equipe do projeto.

As possibilidades de ações democráticas do projeto estiveram presentes no interesse de divulgar conhecimento acadêmico e cultural de forma divertida em um meio de comunicação de massa, dando ênfase a diferentes obras, gêneros musicais e artistas. Embora diversificada, a programação de 2019 não contemplou nenhum artista local, falha que se pretende evitar futuramente. Valorizou-se, por outro lado, a pesquisa na área de estudos literários no Departamento de Letras da Universidade Federal de Viçosa, com convites a docentes e discentes para participarem de entrevistas.

No artigo "Rádios Universitárias Públicas: compromisso com a sociedade e com a informação", referido em outra parte do presente artigo, a professora de Comunicação Sandra de Deus (2003, p. 310) destacou que há um percentual significativo de Universidades Federais com concessão de emissoras de média potência, mas, por não usarem a rádio como "ferramenta a serviço da sociedade e contra os monopólios da informação", parecem desconhecer "o poder de um meio de comunicação de massa como o rádio". Não foi o que se observou na Universitária FM 100,7, que, como já foi destacado, possui uma programação ampla, visando a interrelação ensino, pesquisa e extensão. O diferencial do projeto "Livros e Canções" na Rádio Universitária FM 100,7 tem relação com o incentivo à leitura de uma maneira lúdica por buscar cons- 
truir e incentivar diálogos criativos entre textualidades diversas. O público, muitas vezes, ignora as aproximações que há entre o erudito e o popular, e, com nossos programas, pensamos em contribuir para tornar mais conhecido esse aspecto marcante da cultura brasileira.

\section{CONSIDERAÇÕES FINAIS}

Falar em programa de rádio hoje pode parecer algo ultrapassado, mas a despeito dessa aparência, os avanços da internet possibilitaram agregar mais mecanismos que colaboram para a propagação das rádios. Hoje, além de podermos ouvir com mais facilidade a rádio de nossa preferência no carro, em casa, pelo computador ou smartphone, podemos disponibilizar os programas em plataformas de streaming e divulgá-los nas redes sociais para que o público acesse quando desejar.

Depois de um ano de execução das atividades do projeto "Livros e Canções", concorremos mais uma vez ao Edital 04/2019 da Pró-Reitoria de Extensão e Cultura da UFV e fomos contemplados novamente com uma bolsa de Iniciação à Extensão para um discente de graduação. Pretendemos aprimorar os roteiros e, futuramente, publicar em livro os melhores programas de nossas temporadas.

Tendo chegado ao final dessa breve reflexão, lembremo-nos do que escreveu José Miguel Wisnik (2004) sobre a música popular do Brasil ser um campo dos mais importantes para que se possa pensar o que é ser brasileiro. O diálogo entre literatura e música popular precisa ser demonstrado ao grande público que, muitas vezes, conhece a poesia cantada na voz de grandes intérpretes da canção brasileira e poderia se interessar também por conhecer o texto literário que dialoga com essa canção, passando a reconhecer as diversas relações que há entre livros e canções e entre cultura erudita e popular. Com o projeto, tivemos oportunidade de observar esse aspecto na prática e, na nova temporada, planejamos explorar com mais propriedade a leitura das canções de nossos programas.

Tentamos constantemente evitar comentários críticos que pudessem substituir as obras, ou seja, buscamos apresentar as obras de modo a estimular outras práticas de 
leituras. A realização do primeiro ano do projeto foi avaliada pela equipe como uma oportunidade de crescimento multidisciplinar, integrando diversos conhecimentos à formação acadêmica e pessoal, merecendo destaque a ampliação do repertório cultural dos membros da equipe e do público ouvinte por estimular a leitura das obras divulgadas, o conhecimento crítico e histórico a elas relacionados. Assim, o projeto se fez consonante com os princípios de diversidade cultural e direito ao acesso à arte e cultura, à memória e às tradições, estando de acordo com o que estabelece a Política Nacional de Extensão Universitária e buscando a interação entre ensino, pesquisa e extensão como uma oportunidade a mais de indissociabilidade dessa tríade em prol de uma formação multidimensional e do uso da Rádio Universitária Pública para a divulgação do conhecimento a serviço de uma sociedade mais justa e igualitária. 


\section{REFERÊNCIAS}

BOSI, Alfredo. “Cultura e culturas brasileiras”. Dialética da colonização. São Paulo: Companhia das Letras, 1992.

CHARTIER, Roger. “Morte ou transfiguração do leitor?” In: CHARTIER, Roger. Os desafios da escrita. São Paulo: Editora da UNESP, 2002.

DEUS, Sandra de. "Rádios Universitárias Públicas: compromisso com a sociedade e com a informação". Revista Em questão. Porto Alegre, v.2 n., 2003.

GUIMARAES, Thayz et al. Reportagem. "A comunicação é a ciência do século XXI”. Revista Logos: comunicação e universidade, [S.l.], v. 1, n. 22, nov. 2015. Disponível em: https://www.e-publicacoes.uerj.br/index.php/logos/article/ view/19560/14204. Acesso em 03 ago. 2020.

MARQUES NETO, José Castilho. "Políticas públicas de livro e leitura no Brasil - o que as Pesquisas Retratos da Leitura nos revelam?". Disponível em https://www. prolivro.org.br/2020/11/12/politicas-publicas-de-livro-e-leitura-no-brasil-o-que-as-pesquisas-retratos-da-leitura-nos-revelam/. Acesso em 10 jan. 2021.

MELO, Luciana. Walmir Lima: além da Ilha de Maré - a história de um sambista. Rio de Janeiro: Autografia, 2017.

NESTROVSKI, Arthur. “O samba mais lindo do mundo”. Teresa - Revista de Literatura Brasileira. n. 4/5. São Paulo: USP/ Ed. 34, 2003.

OLIVEIRA, Manuel Botelho. Poesia completa. Introdução, organização e fixação de texto de Adma Muhana. São Paulo, 2005. Disponível em https://www.literaturabrasileira.ufsc.br/documentos/?action=download\&id=43056. Acesso em 29 jul. 2020.

SPENTHOF, Edson Luiz. "A importância das rádios e TVs universitárias como laboratórios". Revista Comun. inf. v. 1, n. 1, p. 153-166, jan. jun. 1998. Disponível em https://www.revistas.ufg.br/ci/article/viewFile/22755/13543. Acesso em 28 out. 2018.

TATIT, Luiz. “Luiz Tatit- letra e música na canção”. [Entrevista publicadas na Plataforma do Letramento]. Disponível em http://www.plataformadoletramento.org.br/ 
em-revista-entrevista-detalhe/851/luiz-tatit-letra-e-musica-na-cancao-popular.html. Acesso em 10 jan. 2021.

ZAPPONE, Mirian Hisae Yaegashi. As Dificuldades da Leitura no Brasil. On-line: Grupo de Estudos em Literatura Brasileira Contemporânea. Disponível em http:// gelbcunb.blogspot.com.br/2017/04/as-dificuldades-da-leitura-no-brasil.html? spref=fb. Acesso em 10 jan. 2021.

WISNIK, José Miguel. "Gaia ciência - literatura e música popular no Brasil”. Sem receita. Editora Publifolha, 2004.

WISNIK, José Miguel. “Machado Maxixe: o caso Pestana”. Teresa - Revista de Literatura Brasileira. n. 4/5. São Paulo: USP/ Ed. 34, 2003.

SITES

FORPROEXT. “Política Nacional de Extensão Universitária”. 2012. Disponível em http:// www.pec.ufv.br/wp-content/uploads/2016/05/2012-07-13-Politica-Nacional-de-Extensao.pdf. Acesso em 10 jan. 2021.

FRATEVI. "Programas de Rádio". Disponível em https://fratevi.org.br/programas/ $\underline{\text { radio }}$ Acesso em 10 jan. 2021.

LITERATURA E MÍDIA. “Livros e canções”. Disponível em https://literaturaemidia. ufv.br/projetos/livros-e-cancoes-2/. Acesso em 10 jan. 2021.

PLATAFORMA PRÓ-LIVRO. “Retratos da Leitura no Brasil”. Disponível em http:// plataforma.prolivro.org.br/retratos.php. Acesso em 10 jan. 2021.

PRÓ-REITORIA DE EXTENSÃO E CULTURA DA UFV. “Edital No 04/2018”. Disponível em http://www.pec.ufv.br/wp-content/uploads/2018/09/EDITAL-PIBEX-2019. pdf. Acesso em 10 jan.2021.

RÁDIO UNIVERSITÁRIA FM 100,7. Disponível em https://fratevi.org.br/paginas/ radioPlayer.php. Acesso em 10 jan. 2021. 
Audiovisual

PALAVRA (En)Cantada. (Documentário). Direção Helena Solberg. Elenco: Chico Buarque de Holanda, Adriana Calcanhoto, Tom Zé, Maria Bethânia et al. Brasil: Radiante Filmes, 2009. (cor/83 min). 